УДК 332.1

DOI: $10.33764 / 2687-041 X-2021-2-53-57$

\title{
АНАЛИЗ РЕЗУЛЬТАТОВ РЕАЛИЗАЦИИ ПРОГРАММЫ РЕНОВАЦИИ НА ТЕРРИТОРИИ ГОРОДА МОСКВЫ
}

\section{Татьяна Викторовна Иванова}

Сибирский государственный университет геосистем и технологий, 630108, Россия, г. Новосибирск, ул. Плахотного, 10, обучающийся, тел. (383)361-01-09, e-mail: tatyanka-TANYA-ivanova@mail.ru

\section{Алексей Викторович Дубровский}

Сибирский государственный университет геосистем и технологий, 630108, Россия, г. Новосибирск, ул. Плахотного, 10, кандидат технических наук, зав. кафедрой кадастра и территориального планирования, тел. (383)361-01-09, e-mail: avd5@ssga.ru

В статье рассматриваются примеры покупки квартир, которые попали под программу реновации, по завышенной стоимости, а стоимость резко возросла до 50 \%. Также рассматриваются преимущества и риски приобретения квартир. В первую очередь это выгодно самому сильному участнику всего процесса - инвесторам. Будущие проблемы игнорируются, и покупатели вынуждены покупать недвижимость, которая строится для них.

Ключевые слова: реновация, риски приобретения

\section{ANALYSIS OF THE RESULTS OF RENOVATION PROGRAM IN THE TERRITORY OF THE CITY OF MOSCOW}

\section{Tatyana V. Ivanova}

Siberian State University of Geosystems and Technologies, 10, Plakhotnogo St., Novosibirsk, 630108, Russia, Student, phone: (383)361-01-09, e-mail: tatyanka-TANYA-ivanova@mail.ru

\section{Alexey V. Dubrovsky}

Siberian State University of Geosystems and Technologies, 10, Plakhotnogo St., Novosibirsk, 630108, Russia, Ph. D., Head of the Department of Cadastre and Territorial Planning, phone: (383)361-01-09, e-mail: avd5@ssga.ru

The article discusses examples of buying apartments that were under renovation at an inflated cost, and the cost increased sharply to $50 \%$. The risks of purchasing apartments and the advantages of purchasing them are also considered. First of all, this is beneficial to the strongest participant in the entire process - investors. Future problems are ignored, and buyers are forced to buy real estate that is being built for them.

Keywords: renovation, acquisition risks

Программа реновации жилья в Москве, утвержденная мэром Москвы в августе 2017 года, набрала обороты. На тот момент программа включала 351 стартовую площадку для строительства новых жилых домов общей площадью более 5 миллионов квадратных метров. К концу 2019 года около 12 тысяч москвичей переехали в новое жилье по программе реновации, а с 2021 года планируют переселять до 25 тысяч человек ежегодно [7]. 
Согласно московскому законодательству, собственники квартир в домах, включенных в программу реновации, гарантированно получают «равноценное» жилье при заселении - с таким же количеством комнат. При этом общая площадь новых квартир в итоге оказывается больше за счет увеличения площади кухни и прихожей. Новые квартиры предоставляются владельцам в том же районе, где они ранее проживали.

Владельцы старых квартир также могут получить квартиру больше или с другим количеством комнат, заплатив городу за дополнительные квадратные метры. При такой покупке жилья переселенцам предоставлялась скидка в размере $10 \%$.

Первые хрущевки по программе реновации ветхого жилья были расселены к зиме 2018 года. Жильцы ветхих пятиэтажек получили квартиры неподалеку в 18-этажной новостройке (рис. 1).

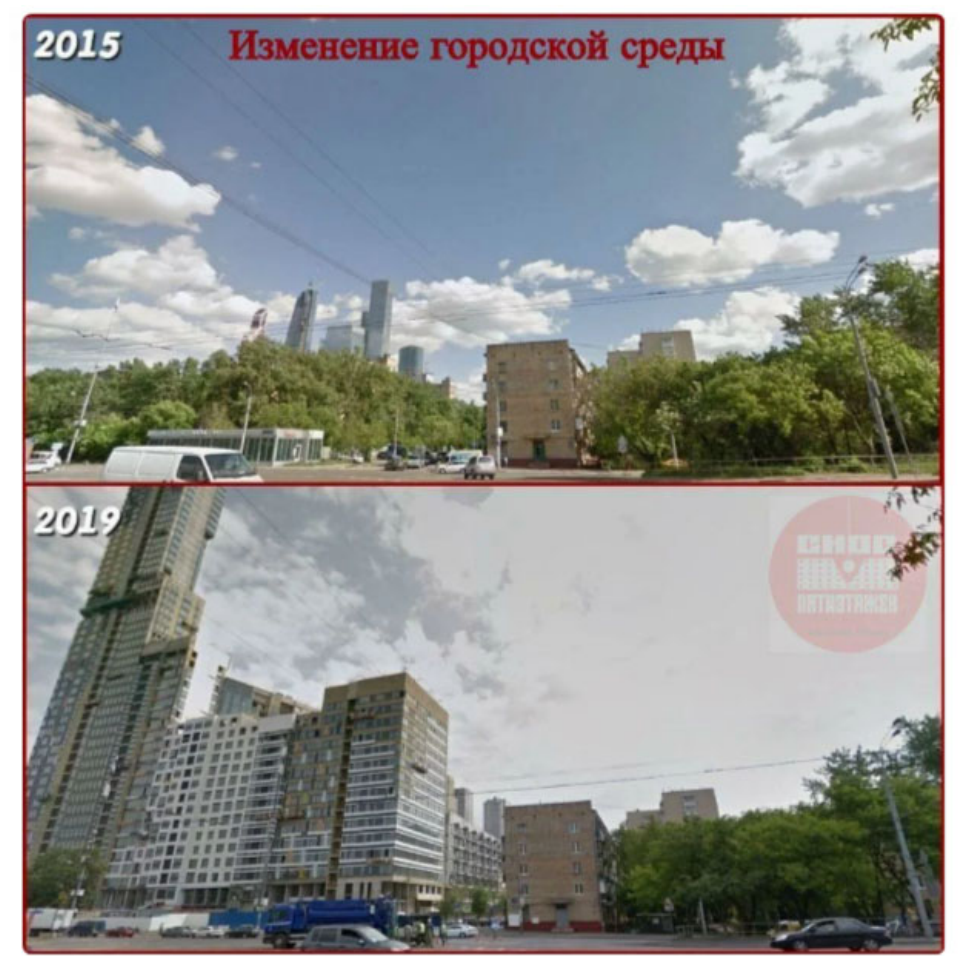

Рис. 1. Изменение городской среды в г. Москве

При получении такого рода жилья имеется ряд плюсов:

- появляется возможность получить квартиру комфорткласса в современном доме;

- новая квартира по закону будет отвечать всем санитарным требованиям и жилищным нормам;

- при строительстве новых объектов недвижимости в перспективе произойдет улучшение социально-бытовой и транспортной инфраструктуры в районе проживания;

- рыночная стоимость нового объекта недвижимости будет больше, чем снесенного по программе реновации. 
Сейчас на рынке недвижимости Москвы сложилась ситуация, когда квартиры в домах, включенных в программу реновации, приобретаются в большинстве случаев только с целью инвестирования. Из-за физического износа не выгодно покупать такую недвижимость только для удовлетворения потребности в жилье. Несмотря на это цены на квартиры в домах, попавших в программу реновации значительно выше аналогов, а уровень комфорта ниже, чем в домах, построенных в 1980-2000 годах.

Несмотря на то, что такие объекты продаются по завышенной цене, покупатель имеет возможность заработать на разнице в стоимости, получив большую площадь квартиры в новостройке. Например, в старых пятиэтажках площадь типовой однокомнатной квартиры составляет 30-35 квадратных метров, что по современным меркам соответствует понятию «квартира -студия». По программе реновации собственники получат в качестве альтернативы полноценные однокомнатные квартиры большей площади и, соответственно, более высокой стоимости. Капитализация инвестиций может достигать 30-50 \%.

Вторая категория покупателей такой недвижимости - это те, кто покупает квартиру в старом фонде для личного проживания с перспективой получения квадратных метров в новом доме. Основной целью этой категории покупателей является улучшение жилищных условий. При отсутствии средств на улучшение жилищных условий, покупка недвижимости в доме под снос - это хорошая возможность приобрести квартиру в новостройке по самой доступной цене.

При покупке квартиры в доме «под реновацию» есть риски, которые можно разделить на два вида. Первый вид риска связан с группой факторов, которые обозначают общий уровень неопределенности при принятии решения о покупке объекта недвижимости с его перспективным сносом и строительством нового объекта недвижимости, покупка которого и является первичной целью сделки. Среди таких факторов можно выделить:

- время проведения реновации, актуальным является вопрос - когда будет построен дом для переселения жителей дома, в котором приобретена квартира;

- выбор места, где именно будет построен новый дом, насколько близко к объектам социально-бытовой и транспортной инфраструктур района;

- какого качества будет новостройка.

Основные риски связаны, во-первых, с тем, что программа реновации находится на начальной стадии своего развития. До сих пор нет четкого плана сноса ветхого жилья во всех районах Москвы, а значит, не определены и точные сроки расселения. Во-вторых, остаются вопросы по качеству жилья, предоставляемого по программе. Новые квартиры могут иметь пониженные потребительские характеристики: плохая планировка, плохая звукоизоляция и утепление, плохо выполненная отделка, а сами дома могут располагаться в плохих местах.

Например, в качестве альтернативы старому жилью вместе с развитой инфраструктурой можно предложить квартиру в менее развитом районе или промышленной зоне, хотя административная принадлежность территории останется прежней. Из-за этого у инвесторов могут возникнуть сложности с продажей, полученной по программе реновации недвижимости. 
Второй тип риска связан с правовыми аспектами совершения сделки «купли продажи» объекта недвижимости. Покупателю необходимо тщательно проверить всю юридическую информацию о квартире, документы на нее, отследить все предыдущие передачи прав собственности и права пользования.

На данный момент в Москве люди определенно настроены негативно на программу реновации, в связи с тем, что раньше жили рядом с парком в хорошем районе в хрущевках с маленьким количеством этажей, а теперь они вынуждены переезжать в дома, где количество этажей увеличилось, а парковочных мест там тоже не хватает, озеленение плохое, слабая обеспеченность новых домов необходимой инфраструктурой, то есть качество жизни снижается.

Таким образом, следует учитывать, что покупка объекта недвижимости, попадающего под действие программы реновации это инвестиции с высоким уровнем неопределенности и многовариантности в развитии ситуации с объектом недвижимости права на который могут возникнуть в будущем. Для проведения экспертного анализа и оценки уровня рисков необходимо использовать долгосрочные модели прогнозирования экономического роста как для Российской Федерации, так и для мировой экономики в целом. Как показывает современная ситуация по развитию экономического кризиса из-за пандемии короновируса реализация многих социально-значимых проектов может быть приостановлена [11].

\section{БИБЛИОГРАФИЧЕСКИЙ СПИСОК}

1. Дубровский, А. В. Особенности формирования рыночной стоимости жилой недвижимости в городах разных классификационных групп [Текст] / А.В. Дубровский, Е. А. Попп // Интерэкспо ГЕО-Сибирь. XIV Междунар. науч. конгр., 23-27 апреля 2018 г., Новосибирск : Междунар. науч. конф. «Экономическое развитие Сибири и Дальнего Востока. Экономика природопользования, землеустройство, лесоустройство, управление недвижимостью» : сб. материалов в 2 т. Т. 2. - Новосибирск : СГУГиТ, 2018. - С. 112-117.

2. Батин, П. С. Перспективное планирование развития городской территории с учетом проектного срока эксплуатации существующих зданий и сооружений [Текст] / П. С. Батин, А. В. Дубровский, О. О. Твердовская, В. П. Шабалина. - Междунар. науч. конф. студентов и молодых ученых «Молодежь. наука. технологии» : сб. материалов. - Новосибирск : СГУГиТ, 2017. - C. $120-125$.

3. Улицкая, Н.Ю. Реновация жилья [Текст]/ Н.Ю. Улицкая, Т.В. Толстова, Т.Г. Аширова. Вектор экономика №4 (22), 2018. - Пермь: Индивидуальный предприниматель Мухин Максим Николаевич, 2018. - С. $35-42$.

4. Кириллова, А. Н. Программа реновации жилищного фонда как фактор системного обновления и устойчивого развития городской застройки [Текст] / А. Н. Кириллова. - Недвижимость: экономика, управление №3, 2017. - М.: Национальный исследовательский Московский государственный строительный университет, 2018. - С. 16-21.

5. Дроздова И. В. Моделирование инвестиционного фонда комплексной реконструкции городской жилой застройки [Текст] / И.В. Дроздова. -Проблемы современной экономики №2 (26), 2008 г.- СПб.: НПК «Рост», 2008. - $277-281$.

6. Индикаторы рынка недвижимости [Электронный ресурс] - Режим доступа: https://www.irn.ru/. - Загл. с экрана.

7. Риски покупателей в домах «под реновацию» [Электронный ресурс] - [Режим доступа] - [https://www.novostroy.ru/articles/interview/chem-risk..]. 
8. Дом. МИНЖКХ [Электронный ресурс] - Режим доступа: http://dom.mingkh.ru/primorskiy-kray/vladivostok. - Загл. с экрана.

9. Дубровский, А.В. Перспективное районирование территории для цели рационального использования в хозяйственной деятельности [Текст] /А.В. Дубровский, - Междунар. науч. конф. «Экономическое развитие Сибири и Дальнего Востока. Экономика природопользования, землеустройство, лесоустройство, управление недвижимостью»: сб. материалов - Новосибирск: СГУГиТ, 2016.

10. Экономику России ждут пять шоков в результате пандемии коронавируса /NEWS// [электронный ресурс] - https://www.newsru.com/finance/09apr2020/rus5shocks.html

11. Хендрикс, А. Реновация в восточной Германии: программа поддержки «исчезающих» городов [Текст] / А. Хедрикс, Н. В. Волович. - Имущественные отношения в Российской Федерации, №5 (200), 2018 г. - М.: Международная академия оценки и консалтинга, 2018. С. 26-42.

(C) Т. В. Иванова, А. В. Дубровский, 2021 